\title{
Pharmacological Activation of Group-II Metabotropic Glutamate Receptors Corrects a Schizophrenia-Like Phenotype Induced by Prenatal Stress in Mice
}

\author{
Francesco Matrisciano*, ${ }^{1,2}$, Patricia Tueting', Stefania Maccari ${ }^{3}$, Ferdinando Nicoletti ${ }^{2,4}$ \\ and Alessandro Guidotti' \\ 'The Psychiatric Institute, Department of Psychiatry, College of Medicine, The University of Illinois at Chicago, Chicago, IL, USA; ${ }^{2}$ Department \\ of Physiology and Pharmacology, University of Rome 'Sapienza', Rome, Italy; ${ }^{3}$ Neuroplasticity Team - CNRS UMR 8576/UGSF, North University \\ of Lille I, Lille, France; ${ }^{4}$ INM Neuromed, Pozzilli, Italy
}

\begin{abstract}
Prenatal exposure to restraint stress causes long-lasting changes in neuroplasticity that likely reflect pathological modifications triggered by early-life stress. We found that the offspring of dams exposed to repeated episodes of restraint stress during pregnancy (here named 'prenatal restraint stress mice' or 'PRS mice') developed a schizophrenia-like phenotype, characterized by a decreased expression of brain-derived neurotrophic factor and glutamic acid decarboxylase 67, an increased expression of type-I DNA methyl transferase (DNMTI) in the frontal cortex, and a deficit in social interaction, locomotor activity, and prepulse inhibition. PRS mice also showed a marked decrease in metabotropic glutamate 2 (mGlu2) and mGlu3 receptor mRNA and protein levels in the frontal cortex, which was manifested at birth and persisted in adult life. This decrease was associated with an increased binding of DNMTI to CpG-rich regions of mGlu2 and mGlu3 receptor promoters and an increased binding of MeCP2 to the mGlu2 receptor promoter. Systemic treatment with the selective $\mathrm{mGlu2} / 3$ receptor agonist LY379268 (0.5 mg/kg, i.p., twice daily for 5 days), corrected all the biochemical and behavioral abnormalities shown in PRS mice. Our data show for the first time that PRS induces a schizophrenia-like phenotype in mice, and suggest that epigenetic changes in mGlu2 and mGlu3 receptors lie at the core of the pathological programming induced by early-life stress. Neuropsychopharmacology (2012) 37, 929-938; doi:I0.1038/npp.20। I.274; published online I6 November 20 I I
\end{abstract}

Keywords: schizophrenia; epigenetics; metabotropic glutamate receptors

\section{INTRODUCTION}

Perinatal exposure to stressful events triggers a maladaptive epigenetic programming that results in permanent changes in neuronal plasticity and behavior (Meaney and FergusonSmith, 2010; McGowan et al, 2011; Szyf, 2011). In rats, low maternal care in the first week of life causes increased responsiveness of the hypothalamic-pituitary-adrenal axis to stress, enhanced emotionality, and impaired spatial learning and object recognition in offspring as they mature (Liu et al, 1997, 2000; Caldji et al, 1998; Weaver et al, 2006; Toki et al, 2007). Adult rats that had been exposed to prenatal stress; ie, the offspring of dams exposed to prenatal restraint stress (PRS) during pregnancy, show abnormal

*Correspondence: Dr F Matrisciano, University of Illinois at Chicago (UIC), Department of Psychiatry, 1601 West Taylor Street, Chicago, IL 606 I2, USA, Tel: + | 312355 2438, Fax: + I 3124134569 ,

E-mail: fmatrisciano@hotmail.com

Received 21 July 201 I; revised I October 201 I; accepted 5 October 2011 hippocampal levels of brain-derived neurotrophic factor (BDNF) and phosphorylated cAMP responsive element binding protein, reduced neurogenesis in the hippocampal dentate gyrus, and sex-dependent abnormalities in behavioral tasks that have preclinical validity as tests for depression and anxiety (Lemaire et al, 2000; MorleyFletcher et al, 2011; Maccari and Morley-Fletcher, 2007; Darnaudéry and Maccari, 2008; Vallée et al, 1999; McCormick et al, 1995). Potentially, linking the biochemical and behavioral aspects of PRS to the pathophysiology of schizophrenia is the evidence that male PRS rats show a reduced expression of group-II metabotropic glutamate (mGlu) receptors (ie, mGlu2 and mGlu3 receptors) in the hippocampus (Zuena et al, 2008). The mGlu2 and mGlu3 receptors are diffusely expressed in the CNS, and act as inhibitory presynaptic receptors mainly at glutamatergic and GABAergic nerve terminals (reviewed by Pin and Duvoisin, 1995; Nicoletti et al, 2011). The mGlu2/3 receptor agonists show robust activity in a range of animal models used to predict anxiolytic (Swanson et al, 2005) and antipsychotic properties (Schoepp and Marek, 2002; Conn 
et al, 2008; Gerwirtz and Marek, 2000; Benneyworth et al, 2007; Patil et al, 2007; Egan et al, 2004; Bishop et al, 2005), and reduce electrophysiological and behavioral effects of hallucinogens (Amitai and Markou, 2010; Marek 2010; Moghaddam and Adams, 1998). In addition, the mGlu2/3 receptor agonist LY404039 improves ratings for positive and negative symptoms in patients suffering from schizophrenia (Patil et al, 2007).

Here, we developed and characterized an experimental mouse model in offspring of PRS mothers to study the effect of in-uterus stress exposure on adult life end points related to schizophrenia.

We report here that the adult offspring of mice subjected to PRS stress during pregnancy (indicated as 'PRS mice') show behavioral and epigenetic changes that are consistent with a schizophrenia-like phenotype. These changes include: (i) a reduced expression of both mGlu 2 and mGlu 3 receptors in the frontal cortex manifested from the first day of postnatal life; (ii) changes in the expression of schizophrenia-related genes, such as $B D N F$, glutamic acid decarboxylase $(G A D) 67$, and DNA methyltransferase (DNMT)-1, and (iii) abnormalities in social interaction, locomotor activity, and prepulse inhibition (PPI) of startle. Remarkably, all these changes were reversed by systemic treatment with the selective mGlu2/3 receptor agonist LY379268.

\section{MATERIALS AND METHODS}

\section{Material}

(-)-2-Oxa-4-aminobicyclo[3.1.0] hexane-4,6-dicarboxylic acid (LY379268) was purchased from Tocris (Ellisville, MO, USA).

\section{Animals and PRS Procedure}

Pregnant mice were individually housed with a 12-h lightdark cycle and food, and water ad libitum. Control dams were left undisturbed throughout gestation, whereas stressed dams were subjected to repeated episodes of restraint stress, as described previously in rats (Maccari et al, 1995), and here adapted for mice by Dr Matrisciano. The stress procedure consisted of restraining the pregnant dam in a transparent tube $(12 \times 3 \mathrm{~cm})$ under a bright light for $30 \mathrm{~min}$ two times per day from the seventh day of pregnancy until delivery. After weaning (postnatal day 21), male mice were selected for the study and housed separately (four per cage).

\section{RNA Isolation, cDNA Synthesis and Real-Time PCR}

Total RNA was extracted from the mouse frontal cortex with Trizol reagent (Invitrogen). Real-time PCR was performed to measure the mRNA levels of mGlu2 and mGlu3 receptors, BDNF-IX, and GAD67. $\beta$-Actin and glyceraldehyde-3phosphate dehydrogenase (GPDH) were used as an internal control for sample normalization. For each target gene sample the relative abundance value obtained for the reference gene was divided by the value derived from the control sequence in the corresponding target gene. Values were calculated using the following equation: $=2^{-[\mathrm{Ct}(\text { target } \mathrm{gene}) / \mathrm{Ct}(\mathrm{control} \text { gene })]}$. Two micrograms of total
RNA were then employed for cDNA synthesis, using Superscript II reverse transcriptase (Life Technologies, $\mathrm{MD}$, USA) and oligodT ( $\mathrm{T}_{16}, 500 \mathrm{ng}$ ) in a final volume of $20 \mu \mathrm{l}$, according to manufacturer's instructions. Following first strand cDNA synthesis, the reaction volume was increased to $100 \mu \mathrm{l}$ and $1 \mu \mathrm{l}$ of this was used for each polymerase chain reaction. Amplification of mGlu2 and mGlu3 receptors, GAD67, and BDNF-IX were carried out employing the following primers: $m G l u 2$ - forward: 5'-TGGACCGCATCAACCGCGAC-3', reverse: $3^{\prime}$-CCACGG CTGAGTGAGGCACG-5'; mGlu3 - forward: $5^{\prime}$-GGTGGG GCGCTCCAACATCC-3', reverse: 3'-AAGCATTCACGCG GCTGGCT-5'. GAD67-forward: 5'-GAGGAGAGCGGGCC AAGA-3', reverse: $3^{\prime}$-GTGCCGCTCCACACGCC-5'; BDNFIX - forward: 5'-CATGAGACCGGGCAAGTC-3', reverse: $3^{\prime}$-CCTTGGGAGGAATGTGTGAT-5'. $\beta$-actin and GPDH mRNA levels were also measured using the following primers - forward: 5' $5^{\prime}$ CTGTCGAGTCGCTCCACCCG-3', reverse: $\quad 3^{\prime}$-ACATGCCGGAGCCGTTGTCGAC-5';- forward: 5'-GCACTGTGTCCTCGGCCACC-3', reverse: 3'-GGCTGTC TGGGGCCCCTGTA-5', respectively.

Real-time quantitative PCR was performed using a supermix (Brilliant II SYBR Green-QPCR Master Mix, Agilent Technologies). Quantitative PCR conditions included an initial denaturation step of $94^{\circ} \mathrm{C} / 5 \mathrm{~min}$ followed by 40 cycles of $94^{\circ} \mathrm{C} / 30 \mathrm{~s}$ and $60^{\circ} \mathrm{C} / 20 \mathrm{~s}$. Standards, samples, and negative controls (no template) were analyzed in triplicate.

\section{Western Blot Analysis}

Western blot analysis for mGlu2/3 receptors, type-1 DNA methyl transferase (DNMT1), GAD67, and MeCP2 was performed as described previously (Matrisciano et al, 2002). Tissue was homogenized at $4{ }^{\circ} \mathrm{C}$ in RIPA lysis buffer containing $1 \mathrm{mM}$ of a cocktail of protease inhibitors (Sigma), $\mathrm{pH}$ 7.4. In all, $20 \mathrm{mg}$ of proteins was resuspended in a SDS-bromophenol blue reducing buffer. Western blot analysis was carried out using $4-12 \%$ Tris-glycine gel (Invitrogen). After blotting onto a nitrocellulose filter $(0.2 \mu \mathrm{m}$ pore size; Invitrogen), the blots were incubated for $1 \mathrm{~h}$ at room temperature with primary antibodies directed against mGlu2/3 receptors (rabbit polyclonal; $1 \mu \mathrm{g} / \mathrm{ml}$; Upstate), DNMT1 (mouse monoclonal; $0.5 \mu \mathrm{g} / \mathrm{ml}$; Imagenex), GAD67 (mouse monoclonal; $1 \mu \mathrm{g} / \mathrm{ml}$; Millipore), MeCP2 (rabbit polyclonal; $0.5 \mu \mathrm{g} / \mathrm{ml}$; Upstate) or $\beta$-actin (mouse monoclonal; $0.5 \mu \mathrm{g} / \mathrm{ml}$; Sigma) in TTBS buffer (100 mM Tris-HCl; $0.9 \% \mathrm{NaCl} ; 0.1 \%$ Tween $20 ; \mathrm{pH} 7.4$ ). After three washes with TTBS buffer, blots were incubated for $1 \mathrm{~h}$ with peroxydase-conjugated secondary antibodies (Sigma). Densitometric analysis was performed using Storm 860 (Molecular Dynamics, Sunnyvale, California) with the IMAGEQUANT analysis software and the values were expressed as an optical density ratio with respect to $\beta$-actin.

\section{ChIP Assay}

Measurements of DNMT1 binding to the mGlu2 and $m G l u 3$ promoters. Tissue $(10 \mathrm{mg})$ was incubated at $37^{\circ} \mathrm{C}$ for 10 min with $500 \mu \mathrm{l}$ of PBS containing $1 \%$ formaldehyde and a cocktail of protease inhibitors (Sigma). After washing three times with cold PBS, tissue was homogenized in $300 \mu \mathrm{l}$ 
of SDS lysis buffer (supplied by ChIP kit, Upstate). To obtain consistent chromatin fragmentation, the lysates were sonicated for $15 \mathrm{~min}$ on ice (Sonic Dismembrator, Model 500, Fisher Scientific). The ChIP procedure was carried out using a commercial kit (Upstate, no. 17-295). The DNMT1 antibody was used at concentrations of $1 \mu \mathrm{g} / \mathrm{ml}$ and incubated overnight at $4{ }^{\circ} \mathrm{C}$. The antibody specific for DNMT1 labeled a single band at the expected molecular size of $\sim 190 \mathrm{kDa}$ in immunoblotting. An aliquot $(2 \%)$ of the sonicated lysate without antibody (Input) was used for quantification of total DNA in tissue extracts before immunoprecipitation. At the end of the ChIP procedure, the protein/DNA cross-linked nucleosomal chromatin complex immunoprecipitated by the specific antibody was reverse cross-linked with $\mathrm{NaCl}$ at a final concentration of $100 \mathrm{mM}$ at $65^{\circ} \mathrm{C}$ overnight. Samples were then treated with proteinase-K. Protein-free DNA was extracted in phenol/ chloroform, precipitated and washed in ethanol, and used for the detection and quantification of mGlu2 and mGlu3 promoters.

Measurements of MeCP2 binding to mGlu2, mGlu3, GAD67, and BDNF-IX promoters. To indirectly assess the cytosine methylation level of mGlu2, mGlu3, GAD67, and $B D N F-I X$ promoters in the frontal cortex, we used the MeCP2 ChIP assay method as described above.

Samples were incubated overnight at $4{ }^{\circ} \mathrm{C}$ with $\mathrm{MeCP} 2$ antibody (Upstate) at a concentration of $1 \mu \mathrm{g} / \mathrm{ml}$. The purified DNA was resuspended in $20 \mu \mathrm{l}$ of diethylpyrocarbonate water and used for the detection and quantification of target promoters. Using the MethPrimer protocol (Li lab, UCSF), we identified the CpG-rich promoter regions of $m$ Glu2 and $m G l u 3$ promoters. CpG-rich promoter fragments of mGlu2 receptors (from -5000 to $-4800 \mathrm{bp}$ ), $m$ Glu3 receptors (from -500 to $-252 \mathrm{bp}$ ), GAD67 (from -840 to-768 bp), and BDNF-IX (Ma et al, 2009) were measured by quantitative PCR using the following primers: $m$ Glu2 - forward: 5'-TCAAGATCCAGGCCTGGT GG-3', reverse: $5^{\prime}$-ACCTCATAGAAGCCCTGG-3'; mGlu3forward: $5^{\prime}$-TTGCTAGGAAACAGGAG-3' ${ }^{\prime}$, reverse: $5^{\prime}$-AGG GTAGAGTGGGAGGTGG-3'. For the identification of GAD67 and BDNF-IX promoters we used the following primers: GAD67 forward: 5'-GAGGAGAGCGGGCCAAGA-3', reverse: 5'-GTGCCGCTCCACACGCC-3'; BDNF-IX forward: 5'-CAT GAGACCGGGCAAGTC-3', reverse: 5'-CCTTGGGAGGAAT GTGTGAT-3' (Matrisciano et al, 2011).

The levels of immunoprecipitated mGlu2, mGlu3, GAD67, and $B D N F-I X$ promoters were expressed as a percentage of the input DNA that was immunoprecipitated by the MeCP2 (or DNMT1) antibodies using the following equation: \% (DNA-IP/total input) $=2^{[(\mathrm{Ct}(10 \% \text { input)-3.32)-Ct(DNA-IP)] }} \times$ $100 \%$. It has been previously reported that on western blots the MeCP2 antibody recognized only a single band of protein corresponding to a molecular mass of approximately $75 \mathrm{kDa}$ (Dong et al, 2008).

\section{Behavioral Tests}

PND 60 controls (Ctrl) (non-stressed) and PRS male mice were used first to examine the behavioral characteristics in basal conditions (drug or saline-free). For this purpose, we performed, first, the social interaction test in a new environment with an intruder (male mouse of 70 days old), then the locomotor activity, and the PPI at startle. All behavioral tests were performed on consecutive days. After 1 week, mice ( $n=8-10$ per group) were repeatedly injected with LY379268 $(0.5 \mathrm{mg} / \mathrm{kg}$, i.p.; for 5 days, twice per day) or saline. Here, we decided to use LY379268 $0.5 \mathrm{mg} / \mathrm{kg}$ because our group previously reported that LY379268 $0.5 \mathrm{mg} / \mathrm{kg}$ can affect DNA methylation in mouse brain (see Matrisciano et al, 2011). Behavioral tests were performed the day after the last injection. After each test, mice were injected again with LY379268 or saline until the day before the last behavioral test (PPI). All animals were housed in the experimental room an hour before the test session for habituation.

Social interaction. We used the experimental paradigm described by Tremolizzo et al (2005). In brief, individual mice were placed in a novel cage together with a nonaggressive male mouse used as an intruder, and the interaction between the two mice was recorded for $10 \mathrm{~min}$ with a digital video camera (Samsung, Korea). The time spent in social interaction $(\mathrm{s} / 10 \mathrm{~min})$ was scored by two well-trained blind operators. Social interaction was defined by body contact including inspection and ano-genital sniffing. Reliability of measurements was assessed by correlating the scores of the two operators.

Locomotor activity. A computerized Animal Activity Monitoring System with VersaMax software (AccuScan Instruments, Columbus, Ohio) was used for the quantification and tracking of locomotor activity in mice as described previously (Carboni et al, 2004). Each activity cage consisted of a Perspex box $(20 \times 20 \times 20 \mathrm{~cm}$ divided into quadrants $)$ surrounded by horizontal and vertical infrared sensor beams. The total number of interruptions of the horizontal sensors was taken as a measure of horizontal activity, whereas that of vertical sensors was used as a measure of vertical activity. Activity was recorded for $20 \mathrm{~min}$ between 1 and $3 \mathrm{pm}$.

PPI of startle reflex. Startle was recorded using the SR-Lab Startle Response System (San Diego, California). The startle box was programmed to record five $120 \mathrm{~dB}$ startle pulses (broadband noise $30 \mathrm{~ms}$ in duration) at the beginning and end of the $20 \mathrm{~min}$ session for measurement of startle habituation. The trial sequence consisted of the presentation of a 50 pseudo-random trials, 10 for each of the following trials: (i) no stimulus; (ii) a startle-only pulse of $120 \mathrm{~dB}$ for $30 \mathrm{~s}$; and prepulse-startle trials with (iii) $74 \mathrm{~dB}-$, (iv) $78 \mathrm{~dB}$-, and (v) $82 \mathrm{~dB}$-prepulse of $20 \mathrm{~ms}$. The time between the offset of the prepulse and the onset of the startle pulse was $100 \mathrm{~ms}$. Startle amplitude was defined as the maximum amplitude within a $100 \mathrm{~ms}$ window following the presentation of the startle pulse. Intertrial intervals were random (mean ITI $=15 \mathrm{~s}$ ). The amount of inhibition was calculated as the following ratio: mean startle for startleonly trials minus mean startle for prepulse trials divided by mean startle for startle-only trials.

\section{Statistical analysis}

All data were expressed as means \pm SEM. The Student's $t$-test and one-way ANOVA followed by the Newman-Keuls multiple comparison test were used for statistical analysis. 


\section{RESULTS}

\section{PRS Mice Show a Decreased Expression of Group-II mGlu Receptors in the Frontal Cortex}

We measured the transcript of mGlu2 and mGlu3 receptors in the frontal cortex of control and PRS mice immediately after birth, at the time of weaning (postnatal day (PND) 21), and at 2 months of age (PND 60). The mGlu2 and mGlu3 mRNA levels were lower at birth than at PND 21 or PND 60 (Figure 1a).

We focused on the frontal cortex because we have previously demonstrated that activation of $\mathrm{mGlu} 2 / 3$ recep-

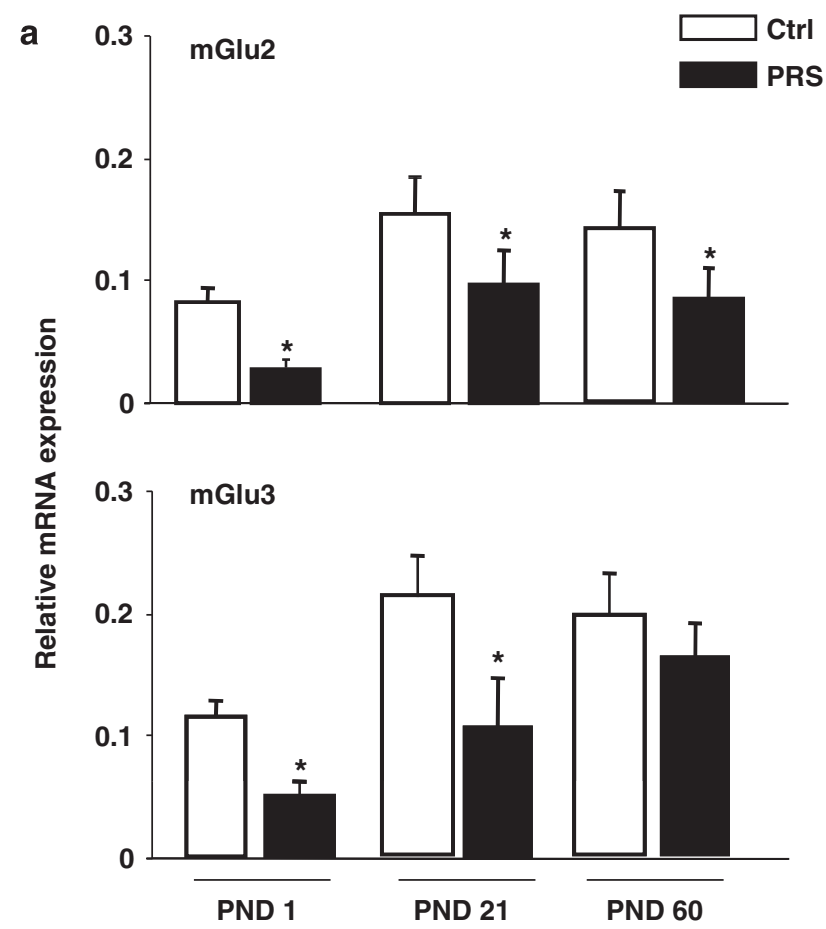

b
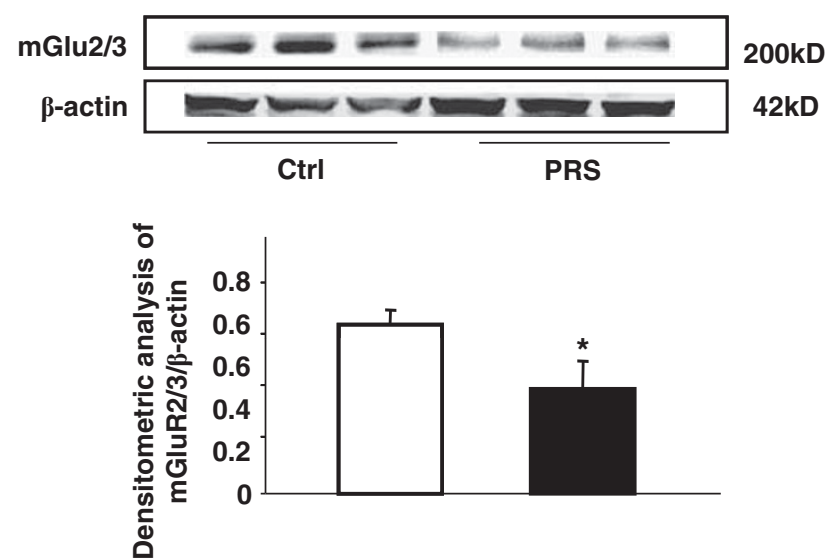

Figure I PRS causes an early and long-lasting reduction in the expression of group-II mGlu receptors in the mouse frontal cortex. mGlu2 and $m$ Glu3 receptors mRNA levels in the frontal cortex (FC) of control (Ctrl) and PRS mice at postnatal day (PND) I (at birth), 2I, and 60 are shown in (a). $\beta$-Actin and GPDH were utilized as internal control. Immunoblot analysis of $\mathrm{mGlu2/3}$ receptors is shown in (b). The representative immunoblot shows the band at $200 \mathrm{kDa}$ corresponding to mGlu $2 / 3$ receptor dimers. All values $(a, b)$ are means \pm SEM of six mice. $* p<0.05$. (Student's $t$-test) vs the corresponding Ctrl value. tors induces epigenetic changes in schizophrenia-related genes in the mouse frontal cortex (Matrisciano et al, 2011).

PRS mice at birth and PND21 showed a marked reduction in mGlu2 and mGlu3 mRNA levels (Figure 1a). In 2-month old PRS mice, we continued to observe a significant decrease in mGlu2 mRNA levels, whereas mGlu3 mRNA levels were unchanged (Figure 1a). We also assessed the expression of $\mathrm{mGlu} 2 / 3$ receptor protein by immunoblotting in the frontal cortex of non-stressed mice as Ctrl and PRS mice at 2 months of age, the same age of the animals used for behavioral analysis. Western blot analysis with an antibody that does not discriminate between mGlu2 and mGlu3 receptors showed a main band at about $200 \mathrm{kDa}$ corresponding to receptor dimers. A marked reduction in the expression of mGlu2/3 receptors was seen in the frontal cortex of PRS mice (Figure 1b).

\section{Epigenetic Effects of PRS on mGlu2 and mGlu3 Receptor Promoters in the Frontal Cortex}

Searching for the mechanisms underlying the reduced expression of group-II mGlu receptors, we examined the levels of DNMT1 and the amount of DNMT1 binding to the CpG-rich promoter region of the mGlu2 and mGlu3 receptor gene. We found increased levels of DNMT1 (Figure 2a) and an increased binding of DNMT1 to CpGrich regions of $m G l u 2$ and $m G l u 3$ receptor promoters in the frontal cortex of 2-month old PRS mice (Figure 2b). To establish whether the increase in binding of DNMT1 to mGlu2/3 promoter regions resulted in an increase of cytosine methylation, we performed a MeCP2 ChIP analysis of $m G l u 2$ and $m G l u 3$ CpG-rich promoter regions. PRS was associated with a substantial increase of MeCP2 bound to $m G l u 2$ receptor gene promoter in the frontal cortex. No significant increase in MeCP2 bound to the CpG-enriched promoter region of the $m G l u 3$ receptor gene of PRS mice was found (Figure 2c). Interestingly, repeated administration of LY379267 reversed the increase in MeCP2 bound to mGlu2 receptor gene promoter; a slight effect was also observed in Ctrl mice, whereas no effects were observed on $m G l u 3$ receptor gene promoter (Figure 2c). To establish whether the increase of $\mathrm{MeCP} 2$ bound to $m G l u 2$ receptor gene promoter was due to an increase in the $\mathrm{MeCP} 2$ protein levels or a result of DNA methylation activity, we measured the MeCP2 protein levels by western blot in FC of Ctrl and PRS mice after saline or LY379268 treatment $(0.5 \mathrm{mg} / \mathrm{kg}$, i.p., twice a day for 5 days) ( $n=5$ per group). No changes in the protein levels of MeCP2 were found in Ctrl or PRS mice (Figure 2d). The immunoblot was carried out with the same antibody used for the MeCP2 binding and showed a singular band at approximately $75 \mathrm{kDa}$. In addition, the effect of LY379268 on MeCP2 binding to mGlu2 gene promoter was associated with an increase in the mGlu2 receptor mRNA levels in PRS mice, whereas a decrease in the mGlu3 mRNA levels was found Figure 2e. The opposite effect of LY379268 on the expression of mGlu2 and mGlu3 receptors mRNA levels might be explained with the different mechanisms that regulate their desensitization after repeated treatment with mGlu2/3 receptors agonist (See Matrisciano et al, 2005; Iacovelli et al, 2009). Taken together, these data suggest that the mGlu2/3 receptors agonist LY379268 affects DNA methylation/demethylation and that mGlu2 and mGlu3 

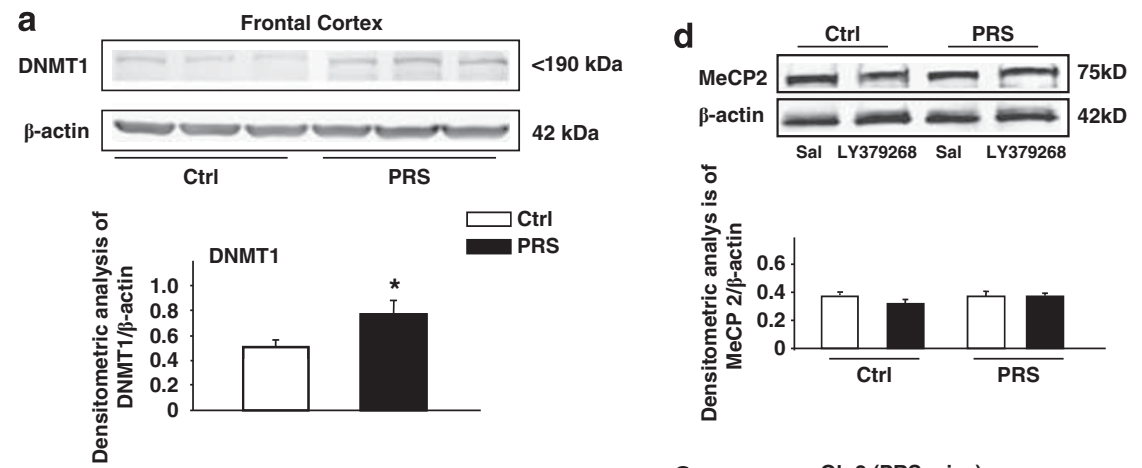

b

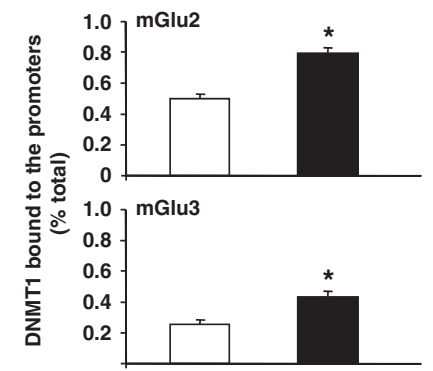

C

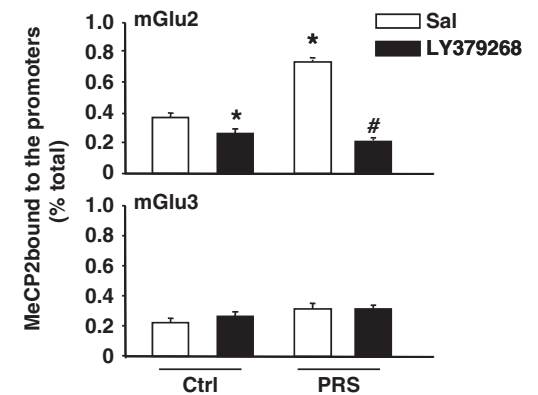

훙
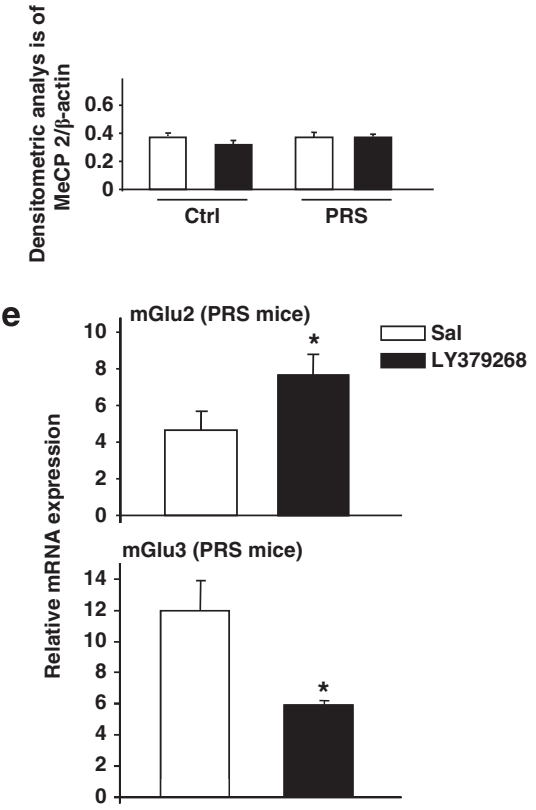

Figure 2 PRS causes an increased expression of DNMTI and an increased amount of DNMTI bound to the mGlu2 and mGlu3 receptor gene promoter in the frontal cortex of PND 60 mice; and an increased MeCP2 bound to the $\mathrm{mGlu2}$ gene promoter reversed by the mGlu2/3 receptors agonist LY379268 $(0.5 \mathrm{mg} / \mathrm{kg}$, i.p.). Immunoblot analysis of DNMTI is shown in (a). The representative immunoblot shows a single band at the expected molecular size of about $190 \mathrm{kDa}$. Data of DNMTI binding to specific promoter regions of the mGlu2 and mGlu3 receptor genes are shown in (b). In (c), increase in the binding of MeCP2 to the mGlu2 receptor promoter in the frontal cortex of PND 60 PRS mice. The effect was totally reversed by the administration of LY379268. A representative immunoblot of MeCP2 in PRS and control (Ctrl) mice after repeated saline or LY379268 injections is shown in (d) ( $n=5$ per group). The expression of mGlu2 and mGlu3 mRNA levels is shown in (e). Values are means \pm SEM of six mice. The mRNA values were normalized by $\beta$-actin and GPDH. ${ }^{*} p<0.05$. (Student's t-test) vs the corresponding Ctrl values or (\#) vs saline.

receptors might have different susceptibilities to the promoter methylation process.

\section{Altered Expression of Schizophrenia-Related Genes in the Frontal Cortex of PRS Mice}

An increase in DNMT levels associated with a downregulation in the gene encoding the GABA-synthesizing enzyme GAD67 was observed in postmortem brain tissue from patients affected by schizophrenia or bipolar disorders (Guidotti et al, 2011) and in brains of rats exposed to early postnatal stress (Meaney and Ferguson-Smith 2010). In addition, recent studies have shown alterations in BDNF levels in schizophrenic subjects and in animal models of psychosis (Roth et al, 2009; Guo et al, 2010). Here, we report that PRS mice are associated with an increased level of DNMT1 (Figure 2a) and a decreased level of mGlu2/3 receptors (Figure 1a), and that PRS mice also show a marked decrease in GAD67 and BDNF (isoform IX) mRNA levels in the frontal cortex of the offspring at birth and at the time of weaning (PND 21) (Figure 3a). A marked decrease was also observed in BDNF mRNA levels and a slight decrease in GAD67 mRNA levels in the frontal cortex of PRS mice at 2 months of age (Figure 3a).

We also measured GAD67 protein levels in the frontal cortex of mice at 2 months of age. A significant reduction of GAD67 protein levels was seen in the frontal cortex of 2-month old PRS mice (Figure 3b). Taken together, these data suggest that PRS mouse may be a potential animal model of schizophrenia suitable for validating new compounds with potential antipsychotic activity.

\section{Changes in the Expression of DNMT1 and GAD67 in Adult PRS Mice were Reversed by Pharmacological Activation of mGlu2/3 Receptors}

Systemic treatment with the mGlu2/3 receptor agonist LY379268 $(0.5 \mathrm{mg} / \mathrm{kg}$, i.p., twice a day, for 5 days $)$ in 


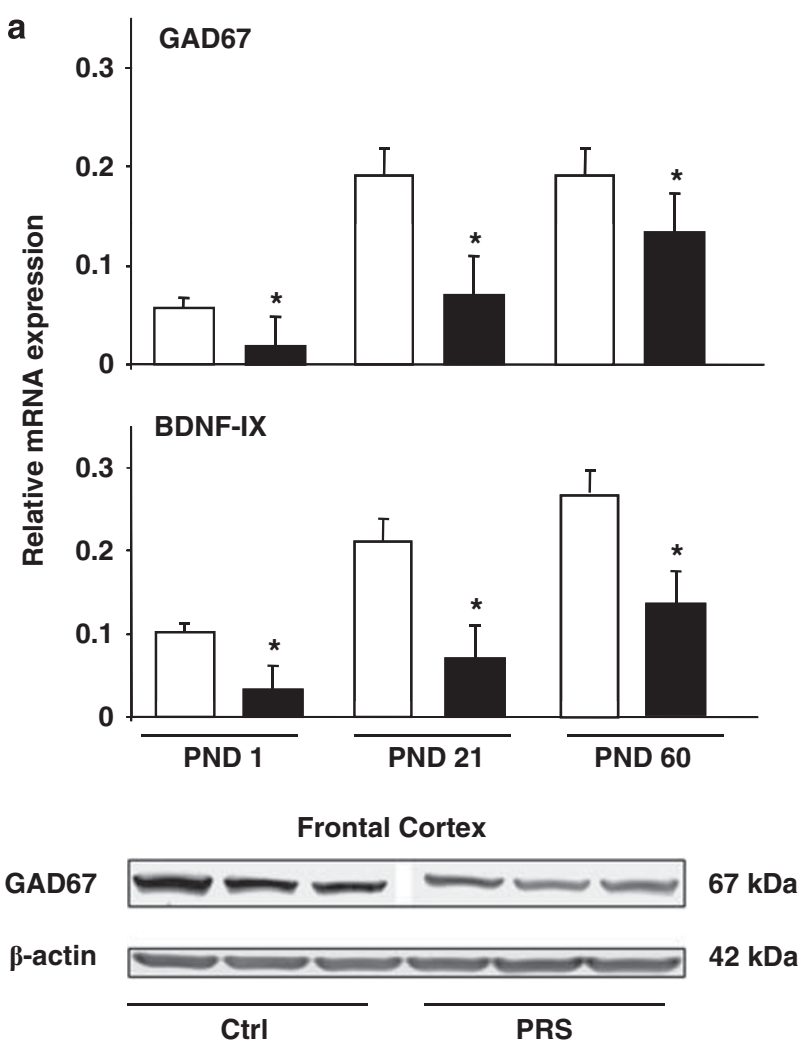

b

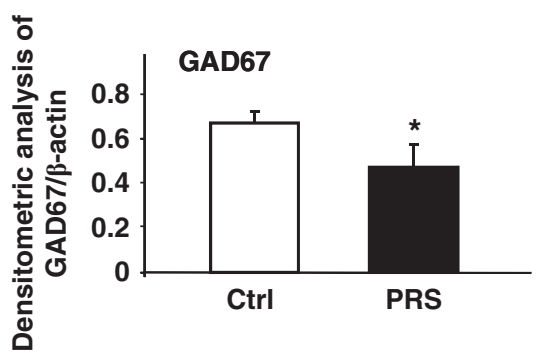

Figure 3 PRS causes an early and long-lasting reduction in the expression of GAD67 and BDNF in the frontal cortex. GAD67 and BDNF-IX mRNA levels in the frontal cortex of control (Ctrl) and PRS mice at PND I, 21, and 60 are shown in (a). Immunoblot analysis of GAD67 is shown in (b). The representative immunoblot shows a single band at the expected molecular size of $67 \mathrm{kDa}$. Values are means \pm SEM of six mice. The mRNA values were normalized by $\beta$-actin and GPDH. ${ }^{*} p<0.05$. (Student's t-test) vs the corresponding Ctrl values.

2-month old PRS mice corrected the biochemical abnormalities seen in the frontal cortex by decreasing DNMT1 and increasing GAD67 protein levels (Figure 4a). No changes were observed on DNMT1 and GAD67 after repeated injection with LY379267 in Ctrl mice (Figure 4a).

We also examined the MeCP2 binding to GAD67 and BDNF gene promoters by $\mathrm{ChIP}$ analysis using $\mathrm{MeCP} 2$ antibody. As shown in Figure 4b, 2-month old PRS mice showed a marked increase in the percentage of MeCP2 binding to the BDNF promoter region, and a significant but a slighter increase in binding to GAD67 promoter in naïve and saline-treated mice. Interestingly, these effects were reversed by treatment with LY379268 $(0.5 \mathrm{mg} / \mathrm{kg}$, i.p., for 5 days twice a day) (Figure $4 \mathrm{~b})$. No effects of LY379268 were observed in Ctrl mice.

In addition, we measured the BDNF-IX mRNA levels in FC of PRS mice treated with LY379268 $((0.5 \mathrm{mg} / \mathrm{kg}$, i.p., twice a day, for 5 days) or saline. LY379268 increased the mRNA levels of BDNF-IX in PRS mice (Figure 4b). The increase of BDNF levels induced by LY379268 is in agreement with a previous study in which the authors showed that treatment with LY379268 increases the expression of BDNF in mouse brain (see Di Liberto et al, 2009).

\section{PRS Mice Showed 'Schizophrenia-Like' Behavioral Deficits Corrected by Treatment with LY379268}

We report here that 2-month old PRS mice had no significant impairment in basic functions, including body weight, basic auditory sensitivity, pain sensitivity, and motor coordination. However, PRS mice showed a significant decrease in social interaction with an unfamiliar mouse in a 10-min test period (Figure 5a). Decreased social investigation is considered analogous to social withdrawal (Tremolizzo et al, 2005), which is a well-documented negative SZ symptom. These mice were also characterized by hyperactivity in a novel open-field apparatus (Figure $5 \mathrm{~b}$ ) consistent with an anxiety-like phenotype thought to underlie the positive symptoms of SZ (Van den Buuse, 2010). In addition, adult PRS mice showed a deficit in PPI (Figure 5c), a condition that is reminiscent of the deficit in sensory-motor gating seen in schizophrenic patients (reviewed by Braff et al, 2001).

Repeated administrations of LY379268 $(0.5 \mathrm{mg} / \mathrm{kg}$, i.p., twice a day for 5 days) greatly increased social interaction in PRS mice, and also induced a smaller increase in social interaction in Ctrl mice (see also Matrisciano et al, 2011) (Figure 5a). Treatment with LY379268 also reduced the increased exploratory activity (Figure $5 \mathrm{~b}$ ) and corrected the PPI deficit (Figure 5c) in adult PRS mice.

\section{DISCUSSION}

Our study demonstrates that early-life stress in mice altered some molecular players of epigenetic mechanisms that are translated into a schizophrenia-like phenotype. This supports the causative role of stress in the pathogenesis of early onset psychosis and schizophrenia (Matrisciano et al, 2011; Dong et al, 2008; Van Os et al, 2010; Spauwen et al, 2004; Guo et al, 2010). PRS mice showed changes in DNMT1, GAD67, and BDNF that were manifested at birth and persisted at least until 2 months of age. DNMTs and GAD67 have been closely associated with schizophrenia. GAD67 and other proteins related to GABAergic function, such as reelin and the high affinity GABA transporter GAT1, have been found to be downregulated in specific populations of telencephalic GABAergic neurons of patients with schizophrenia and bipolar disorder (Guidotti et al, 2005; Grayson et al, 1999; Dong et al, 2008; Lewis et al, 2005). Further, downregulation of at least GAD67 and reelin has been related to the overexpression of DNMT (Veldic et al, 2007; Ruzicka et al, 2007). The resulting deficit in GABAergic transmission likely contributes to cognitive and behavioral abnormalities, and to the deficit of sensory-motor gating typical of psychotic patients (Guidotti et al, 2005; Lewis et al, 2005). Changes in BDNF levels were also found in psychotic patients (Guillin et al, 2004; Angelucci et al, 2005; Shoval and Weizman, 2005; Guillin et al, 2007; Lu and 

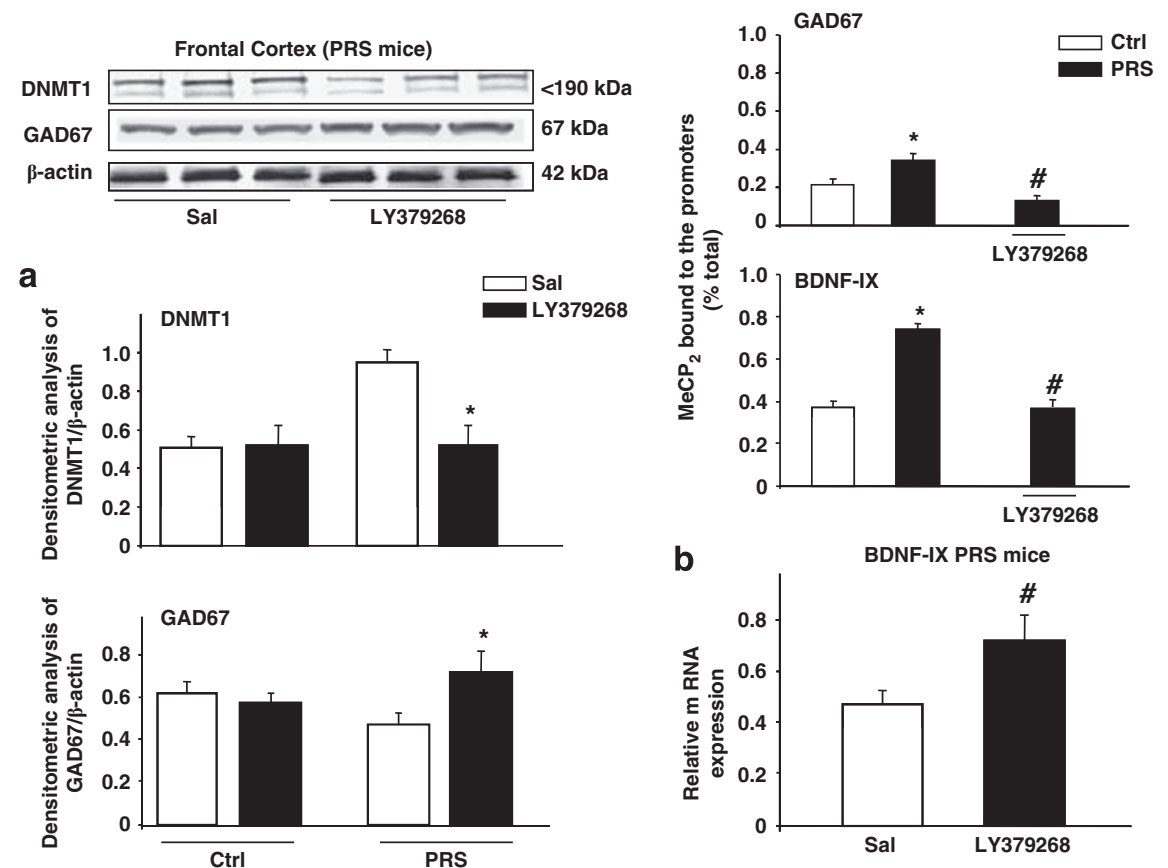

Figure 4 Pharmacological activation of mGlu2/3 receptors corrects the biochemical abnormalities in the frontal cortex of PRS mice. PRS mice were treated with saline (Sal) or LY379268 (0.5 mg/kg, i.p., twice per day for 5 days). A representative immunoblot of DNMTI and GAD67 in PRS mice is shown in (a). Combined densitometric values of DNMTI and GAD67 in control (Ctrl) and PRS mice after saline or LY379268 treatment ( $n=6$ per group). Levels of MeCP2 binding to GAD67 and BDNF-IX promoters, and the effect of LY379268 are shown in (b). In (b) the BDNF mRNA levels in PRS mice after LY379268 treatment. Values are means \pm SEM of six mice. The mRNA values were normalized by $\beta$-actin and GPDH. In (a), *p $<0.05$ (Student's $t$-test) vs the respective values of PRS mice treated with Sal. In (b), ${ }^{*} p<0.05$ (One-way ANOVA + Newman-Keuls) vs values obtained in the offspring of unstressed dams (Ctrl) naïve or saline-treated mice (*) or vs values obtained in PRS mice treated with LY379268 (\#). Values are means \pm SEM of six mice.

Martinowich, 2008; Pillai, 2008; Buckley et al, 2011). In addition, the functional Val66Met polymorphisms of the $B D N F$ gene have been associated with schizophrenia (Rybakowski, 2008). In PRS mice, changes in DNMT1, GAD67, and BDNF in the frontal cortex were combined with abnormalities in behavioral tasks that are known to be responsive to antipsychotic medication such as social interaction, locomotor activity, and PPI (reviewed by Powell and Miyakawa, 2006; Castagné et al, 2009; Van den Buuse, 2010; Moore, 2010). In addition, previous studies reported that abnormal signaling in the BDNF/trk-B pathway may lead to abnormalities in the GABAergic neurons (Hashimoto et al, 2005; Hashimoto and Lewis, 2006). mGlu2/3 receptors are also expressed in GABAergic neurons, and the altered expression of mGlu2 or altered methylation support the hypothesis of glutamatergic/GABAergic dysfunction in schizophrenia.

Thus, PRS mice represent a new behavioral and biochemical model of a schizophrenia-like phenotype endowed with 'construct' and 'pharmacological' validity because it recapitulates the potential link between early-life stress and the pathogenesis of psychosis, and has predictive power for the identification and validation of new treatments in schizophrenia.

PRS mice showed a reduced expression of the genes encoding for mGlu2 and mGlu3 receptors in the frontal cortex at birth and at the time of weaning. This reduction was associated with an increased binding of MeCP2 to 5methylcytosines of the respective gene promoters, suggesting an increasing methylation activity, and therefore, was an integral component of the pathological epigenetic program- ming induced by PRS in mice. We performed the binding of MeCP2 for its role in epigenetic mechanisms. MECP2 is a gene encoding the nuclear protein methyl-CpG binding protein 2, and, in brain, can either repress or activate transcription; when acting as a repressor, $\mathrm{MeCP} 2$ binds to methylated CpG dinucleotides (Chahrour et al, 2008; Nan et al, 1993), and may control gene expression also in a region-dependent manner (Belichenko et al, 1997; Kishi and Macklis, 2005). In this work, no changes of MeCP2 protein levels were found in PRS and Ctrl animals, this suggests that the mGlu2/3 receptors agonist induces 'functional' or 'epigenetic' changes of the target genes that we examined. This effect is also associated with alterations in the MeCP2 binding of $B D N F$ and GAD67 gene promoters and their expression in FC of PRS mice. We may speculate that mGlu2 receptor, BDNF, and GAD67 are functionally related and potential targets of methylation/demethylation activity. In adult life, PRS mice still showed a reduced expression and increased MeCP2 binding of the mGlu2 receptor gene that may reflect a hypermethylation activity, whereas expression and MeCP2 of the mGlu3 receptor gene was unchanged in spite of the increased binding of DNMT1 to CpG-rich regions of the mGlu3 receptor promoter. This suggests the existence of compensatory mechanisms that restrain methylation of the $m G l u 3$ receptor promoter in the frontal cortex of adult PRS mice. The identity of these mechanisms is unknown at present. Our data are in agreement with the evidence that the expression of mGlu2 receptors is reduced in the frontal cortex of the adult offspring, in a mouse model of maternal influenza viral infection, which is known to increase the risk for schizophrenia (Moreno et al, 2011). 

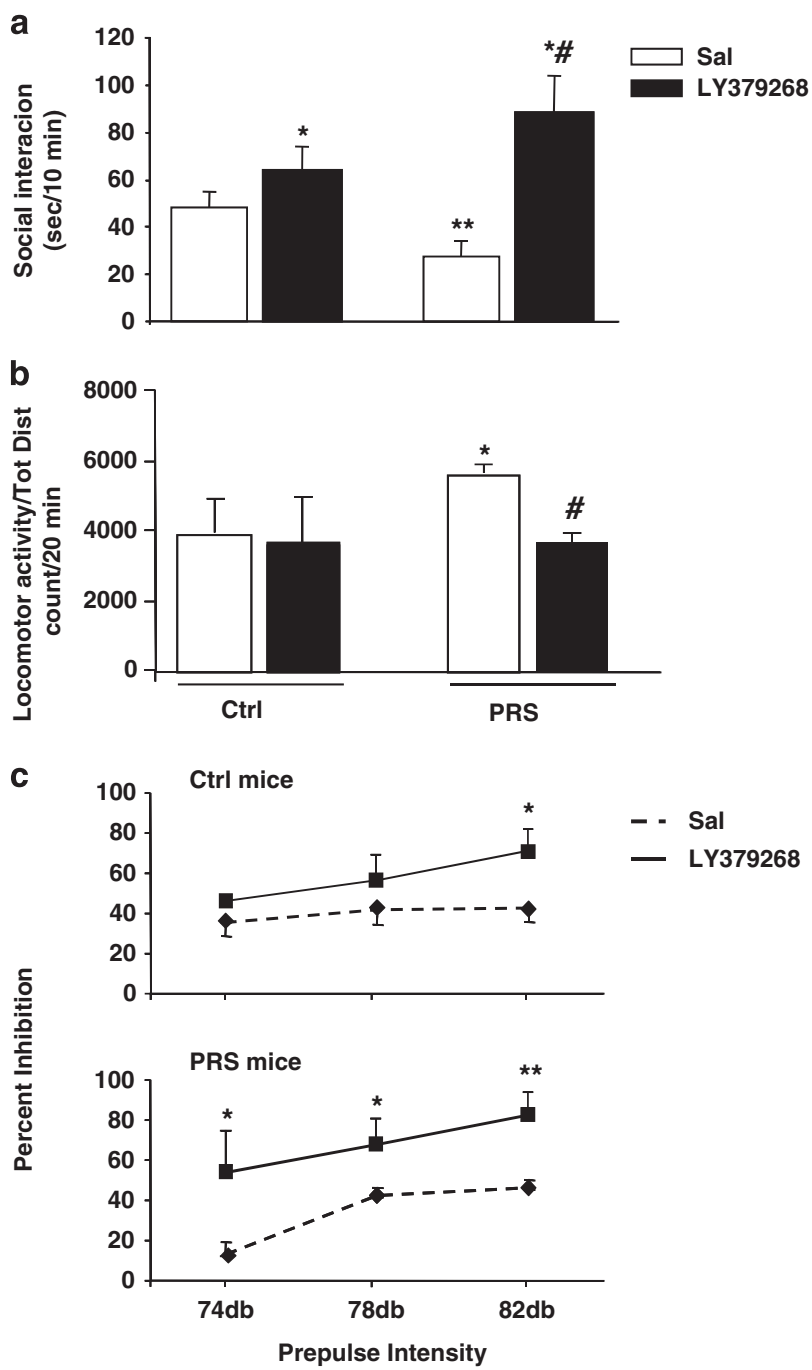

(subtypes mGlu2 and mGlu3) are preferentially located in the pre-terminal region of nerve endings (glutamatergic neurons) where their activation decreases cAMP formation and negatively modulates neurotransmitter release, this occurs at excitatory (glutamatergic), inhibitory (GABAergic), and neuromodulatory (ie, monoamines, ACh, peptides) synapses(Niswender and Conn, 2010), resulting in a neuroprotective effect (Bruno et al, 1995). Activation of mGlu2 and/or mGlu3 receptors might have a strong impact on epigenetic mechanisms by restraining the pathological increase in DNMT1 expression (present data), and in addition, by promoting mechanisms of DNA demethylation (Matrisciano et al, 2011).

Accordingly, we have found that the systemic injection of LY379268 increases the levels of the putative DNAdemethylating protein, growth arrest, and DNA damage in (Gadd) $45-\beta$, as well as the amount of Gadd45- $\beta$ bound to specific promoter regions of reelin, BDNF, and GAD67 in the frontal cortex of mice (Matrisciano et al, 2011). This raises the interesting question of how PRS affects the DNA demethylation machinery in the frontal cortex.

The epigenetic regulation exerted by $\mathrm{mGlu} 2$ and/or mGlu3 receptors suggests that mGlu2/3 receptor agonists may act on mechanisms that lie at the core of the cognitive dysfunction associated with schizophrenia, and therefore may act as 'pathogenetic' rather than 'symptomatic' drugs in the treatment of psychotic disorders.

\section{ACKNOWLEDGEMENTS}

This work was supported in part by the National Institutes of Health, National Institute of Mental Health (Grant MH0708551 to AG).

\section{DISCLOSURE}

Figure 5 PRS causes schizophrenia-like behavioral abnormalities reversed by treatment with LY379268 in mice. Data of social interaction, locomotor activity, and prepulse inhibition (PPI) of the startle reflex are shown in (a), (b), and (c), respectively. Values were means \pm SEM of 8-10 mice. $* p<0.05$ (One-way ANOVA + Newman-Keuls) vs the respective groups of mice treated with saline (Sal) $(*)$, vs the respective control (Ctrl) mice (**), or vs Ctrl mice treated with LY379268 (\#).

In addition, a reduced expression of either mGlu2 or mGlu3 receptors has been reported in the frontal cortex of schizophrenic patients (González-Maeso et al, 2008; Ghose et al, 2009; but see Crook et al (2002) and Gupta et al (2005) for contrasting results). Additionally, variations in the gene encoding human mGlu3 receptors have been associated with a risk for schizophrenia and with the response to antipsychotic medication (Egan et al, 2004; Bishop et al, 2005, 2007; Nicodemus et al, 2007; Fijal et al, 2009; Jönsson et al, 2009). Particularly relevant here is that systemic treatment with the dual orthosteric mGlu2/3 receptor agonist LY379268 reversed all biochemical and behavioral abnormalities of PRS mice, including the increase in DNMT1 expression and the MeCP2 binding to GAD67 and $B D N F$ gene promoters in the frontal cortex. Thus, pharmacological activation of mGlu2/3 receptors may be considered a novel 'epigenetic path' in the experimental treatment of psychotic disorders. Group II receptors

The authors declare no conflict of interest.

\section{REFERENCES}

Amitai N, Markou A (2010). Effects of metabotropic glutamate receptor $2 / 3$ agonism and antagonism on schizophrenia-like cognitive deficits induced by phencyclidine in rats. Eur $J$ Pharmacol 639: 67-80.

Angelucci F, Brenè S, Mathé AA (2005). BDNF in schizophrenia, depression and corresponding animal models. Mol Psychiatry 10: $345-352$.

Belichenko PV, Hagberg B, Dahlstrom A (1997). Morphological study of neocortical areas in Rett syndrome. Acta Neuropathol 93: 50-61.

Benneyworth MA, Xiang Z, Smith RL, Garcia EE, Conn PJ, Sanders-Bush E (2007). A selective positive allosteric modulator of metabotropic glutamate receptor subtype 2 blocks a hallucinogenic drug model of psychosis. Mol Pharmacol 72: 477-484.

Bishop JR, Ellingrod VL, Moline J, Miller D (2005). Association between the polymorphic GRM3 gene and negative symptom improvement during olanzapine treatment. Schizophr Res 77: 253-260.

Bishop JR, Wang K, Moline J, Ellingrod VL (2007). Association analysis of the metabotropic glutamate receptor type 3 gene (GRM3) with schizophrenia. Psychiatr Genet 17: 358. 
Braff DL, Geyer MA, Swerdlow NR (2001). Human studies of prepulse inhibition of startle: normal subjects, patient groups, and pharmacological studies. Psychopharmacology 156: 234-258.

Bruno V, Battaglia G, Copani A, Giffard RG, Raciti G, Raffaele R et al (1995). Activation of class II or III metabotropic glutamate receptors protects cultured cortical neurons against excitotoxic degeneration. Eur J Neurosci 7: 1906-1913.

Buckley PF, Pillai A, Howell KR (2011). Brain-derived neurotrophic factor: findings in schizophrenia. Curr Opin Psychiatry 24: $122-127$

Caldji C, Tannenbaum B, Sharma S, Francis D, Plotsky PM, Meaney MJ (1998). Maternal care during infancy regulates the development of neural systems mediating the expression of fearfulness in the rat. Proc Natl Acad Sci USA 95: 5335-5340.

Carboni G, Tueting P, Tremolizzo L, Sugaya I, Davis J, Costa E et al (2004). Enhanced dizocilpine efficacy in heterozygous reeler mice relates to GABA turnover downregulation. Neuropharmacology 46: 1070-1081.

Castagné V, Moser PC, Porsolt RD (2009). Preclinical behavioral models for predicting antipsychotic activity. Adv Pharmacol 57: 381-418.

Chahrour M, Jung SY, Shaw C, Zhou X, Wong ST, Qin J et al (2008). MeCP2, a key contributor to neurological disease, activates and represses transcription. Science 320: 1224-1229.

Conn PJ, Tamminga C, Schoepp DD, Lindsley C (2008). Schizophrenia: moving beyond monoamine antagonists. Mol Interv 8: 99-107.

Crook JM, Akil M, Law BC, Hyde TM, Kleinman JE (2002). Comparative analysis of group II metabotropic glutamate receptor immunoreactivity in Brodmann's area 46 of the dorsolateral prefrontal cortex from patients with schizophrenia and normal subjects. Mol Psychiatry 7: 157-164.

Darnaudéry M, Maccari S (2008). Epigenetic programming of the stress response in male and female rats by prenatal restraint stress. Brain Res Rev 57: 571-585.

Di Liberto V, Bonomo A, Frinchi M, Belluardo N, Mudò G (2009). Group II metabotropic glutamate receptor activation by agonist LY379268 treatment increases the expression of brain derived neurotrophic factor in the mouse brain. Neuroscience 165: 863-873.

Dong E, Nelson M, Grayson DR, Costa E, Guidotti A (2008). Clozapine and sulpiride but not haloperidol or olanzapine activate brain DNA demethylation. Proc Natl Acad Sci USA 105: 13614-13619.

Egan MF, Straub RE, Goldberg TE, Yakub I, Callicott JH, Hariri AR et al (2004). Variation in GRM3 affects cognition, prefrontal glutamate, and risk for schizophrenia. Proc Natl Acad Sci USA 101: 12604-12609.

Fijal BA, Kinon BJ, Kapur S, Stauffer VL, Conley RR, Jamal HH et al (2009). Candidate-gene association analysis of response to risperidone in African-American and white patients with schizophrenia. Pharmacogenomics J 9: 311-318.

Gerwirtz JC, Marek GJ (2000). Behavioral evidence for interactions between a hallucinogenic drug and group II metabotropic glutamate receptors. Neuropsychopharmacology 23: 569-576.

Ghose S, Gleason KA, Potts BW, Lewis-Amezcua K, Tamminga CA (2009). Differential expression of metabotropic glutamate receptors 2 and 3 in schizophrenia: a mechanism for antipsychotic drug action? Am J Psychiatry 166: 812-820.

González-Maeso J, Ang RL, Yuen T, Chan P, Weisstaub NV, LópezGiménez JF et al (2008). Identification of a serotonin/glutamate receptor complex implicated in psychosis. Nature 452: 93-97.

Grayson DR, Chen Y, Dong E, Kundakovic M, Guidotti A (1999). From trans-methylation to cytosine methylation: evolution of the methylation hypothesis of schizophrenia. Epigenetics 4: 144-149.

Guidotti A, Auta J, Chen Y, Davis JM, Dong E, Gavin DP et al (2011). Epigenetic GABAergic targets in schizophrenia and bipolar bisorder. Neuropharmacology 60: 1007-1016.
Guidotti A, Auta J, Davis JM, Dong E, Grayson DR, Veldic M et al (2005). GABAergic dysfunction in schizophrenia: new treatment strategies on the horizon. Psychopharmacology 180: 191-205.

Guillin O, Demily C, Thibaut F (2007). Brain-derived neurotrophic factor in schizophrenia and its relation with dopamine. Int Rev Neurobiol 78: 377-395.

Guillin O, Griffon N, Diaz J, Le Foll B, Bezard E, Gross C et al (2004). Brain-derived neurotrophic factor and the plasticity of the mesolimbic dopamine pathway. Int Rev Neurobiol 59: 425-444.

Guo C, Yang Y, Su Y, Si T (2010). Postnatal BDNF expression profiles in prefrontal cortex and hippocampus of a rat schizophrenia model induced by MK-801 administration. J Biomed Biotechnol 2010: 783297.

Gupta DS, McCullumsmith RE, Beneyto M, Haroutunian V, Davis KL, Meador-Woodruff JH (2005). Metabotropic glutamate receptor protein expression in the prefrontal cortex and striatum in schizophrenia. Synapse 57: 123-131.

Hashimoto T, bergen SE, Nguyen QL, Xu B, Monteggia LM, Pierri $\mathrm{JM}$ et al (2005). Relationship of brain-derived neurotrophic factor and its receptor $\operatorname{TrkB}$ to altered inhibitory prefrontal circuitry in schizophrenia. J Neuosci 25: 372-383.

Hashimoto T, Lewis DA (2006). BDNF Val66Met polymorphism and GAD67 mRNA expression in the prefrontal cortex of subjects with schizophrenia. Am J Psychiatry 163: 534-537.

Iacovelli L, Molinaro G, Battaglia G, Motolese M, Di Menna L, Alfiero $M$ et al (2009). Regulation of group II metabotropic glutamate receptors by $G$ protein-coupled receptor kinases: mGlu2 receptors are resistant to homologous desensitization. Mol Pharmacol 75: 991-1003.

Jönsson EG, Saetre P, Vares M, Andreou D, Larsson K, Timm S et al (2009). DTNBP1, NRG1, DAOA, DAO and GRM3 polymorphisms and schizophrenia: an association study. Neuropsychobiology 59: 142-150.

Kishi N, Macklis JD (2005). Dissecting MeCP2 function in the central nervous system. J Child Neurol 20: 753-759.

Lemaire V, Koehl M, Le Moal M, Abrous DN (2000). Prenatal stress produces learning deficits associated with an inhibition of neurogenesis in the hippocampus. Proc Natl Acad Sci USA 97: $11032-11037$.

Lewis DA, Hashimoto T, Volk DW (2005). Cortical inhibitory neurons and schizophrenia. Nat Rev Neurosci 6: 312-324.

Liu D, Diorio J, Day JC, Francis DD, Meaney MJ (2000). Maternal care, hippocampal synaptogenesis and cognitive development in rats. Nat Neurosci 3: 799-806.

Liu D, Diorio J, Tannenbaum B, Caldji C, Francis D, Freedman A et al (1997). Maternal care, hippocampal glucocorticoid receptors, and hypothalamic-pituitary-adrenal responses to stress. Science 277: 1659-1662.

Lu B, Martinowich K (2008). Cell biology of BDNF and its relevance to schizophrenia. Novartis Found Symp 289: 119-129.

Ma DK, Jang $\mathrm{MH}$, Guo JU, Kitabatake Y, Chang ML, PowAnpongkul N (2009). Neuronal activity-induced Gadd45b promotes epigenetic DNA demethylation and adult neurogenesis. Science 323: 1074-1077.

Maccari S, Morley-Fletcher S (2007). Effects of prenatal restraint stress on the hypothalamus-pituitary-adrenal axis and related behavioral and neurobiological alterations. Psychoneuroendocrinology 32: S10-S15.

Maccari S, Piazza PV, Kabbaj M, Barbazanges A, Simon H, Le Moal $M$ (1995). Adoption reverses the long-term impairment in glucocorticoid feedback induced by prenatal stress. J Neurosci 15: $110-116$

Marek GJ (2010). Metabotropic glutamate (2/3) mGlu(2/3) receptors, schizophrenia and cognition. Eur J Pharmacol 639: 81-90.

Matrisciano F, Dong E, Gavin DP, Nicoletti F, Guidotti A (2011). Activation of group-II metabotropic glutamate receptors 
promotes DNA demethylation in the mouse brain. Mol Pharm 80: $174-182$.

Matrisciano F, Scaccianoce S, Del Bianco P, Panaccione I, Canudas AM, Battaglia G et al (2005). Metabotropic glutamate receptors and neuroadaptation to antidepressants: imipramine-induced down-regulation of beta-adrenergic receptors in mice treated with metabotropic glutamate $2 / 3$ receptor ligands. J Neurochem 93: 1345-1352.

Matrisciano F, Storto M, Ngomba RT, Cappuccio I, Caricasole A, Scaccianoce $S$ et al (2002). Imipramine treatment up-regulates the expression and function of mGlu2/3 metabotropic glutamate receptors in the rat hippocampus. Neuropharmacology 42: 1008-1015.

McCormick CM, Smythe JW, Sharma S, Meaney MJ (1995). Sex-specific effects of prenatal stress on hypothalamic-pituitaryadrenal responses to stress and brain glucocorticoid receptor density in adult rats. Brain Res Dev Brain Res 84: 55-61.

McGowan PO, Suderman M, Sasaki A, Huang TC, Hallett M, Meaney MJ et al (2011). Broad epigenetic signature of maternal care in the brain of adult rats. PLoS One 28: e14739.

Meaney MJ, Ferguson-Smith AC (2010). Epigenetic regulation of the neural transcriptome: the meaning of the marks. Nat Neurosci 13: 1313-1318.

Moghaddam B, Adams BW (1998). Reversal of phencyclidine effects by a group II metabotropic glutamate receptor agonist in rats. Science 281: 1349-1352.

Moore H (2010). The role of rodent models in the discovery of new treatments for schizophrenia: updating our strategy. Schizophr Bull 36: 1066-1072.

Moreno JL, Kurita M, Holloway T, López J, Cadagan R, MartínezSobrido L et al (2011). Maternal influenza viral infection causes schizophrenia-like 5-HT2A and mGlu2 receptors in the adult offspring. J Neurosci 31: 1863-1872.

Morley-Fletcher S, Mairesse J, Soumier A, Banasr M, Fagioli F, Gabriel C et al (2011). Chronic agomelatine treatment corrects behavioral, cellular, and biochemical abnormalities induced by prenatal stress in rats. Psychopharmacology 217: 301-313.

Nan X, Meehan RR, Bird A (1993). Dissection of the methyl-CpG binding domain from the chromosomal protein MeCP2. Nucleic Acids Res 21: 4886-4892.

Nicodemus KK, Kolachana BS, Vakkalanka R, Straub RE, Giegling I, Egan MF et al (2007). Evidence for statistical epistasis between catechol-O-methyltransferase (COMT) and polymorphisms in RGS4, G72 (DAOA), GRM3, and DISC1: influence on risk of schizophrenia. Hum Genet 120: 889-906.

Nicoletti F, Bockaert J, Collingridge GL, Conn PJ, Ferraguti F, Schoepp DD et al (2011). Metabotropic glutamate receptors: from the workbench to the bedside. Neuropharmacology 60: 1017-1041.

Niswender CM, Conn PJ (2010). Metabotropic glutamate receptors: physiology, pharmacology, and disease. Annu Rev Pharmacol Toxicol 50: 295-322.

Patil ST, Zhang L, Martenyi F, Lowe SL, Jackson KA, Andreev BV (2007). Activation of mGlu2/3 receptors as a new approach to treat schizophrenia: a randomized phase 2 clinical trial. Nat Med 13: $1103-1108$.

Pillai A (2008). Brain-derived neurotropic factor/TrkB signaling in the pathogenesis and novel pharmacotherapy of schizophrenia. Neurosignals 16: 183-193.
Pin JP, Duvoisin R (1995). The metabotropic glutamate receptors: structure and functions. Neuropharmacology 34: 1-26.

Powell CM, Miyakawa T (2006). Schizophrenia-relevant behavioral testing in rodent models: a uniquely human disorder? Biol Psychiatry 59: 1198-1207.

Roth TL, Lubin FD, Sodhi M, Kleinman JE (2009). Epigenetic mechanisms in schizophrenia. Biochim Biophys Acta 1790: 869-877.

Rybakowski JK (2008). BDNF gene: functional Val66Met polymorphism in mood disorders and schizophrenia. Pharmacogenomics 9: 1589-1593.

Ruzicka WB, Zhubi A, Veldic M, Grayson DR, Costa E, Guidotti A (2007). Selective epigenetic alteration of layer I GABAergic neurons isolated from prefrontal cortex of schizophrenia patients using laser-assisted microdissection. Mol Psychiatry 12: 385-397.

Schoepp DD, Marek GJ (2002). Molecular pharmacology of mGlu2/ 3 receptor agonists: novel agents for schizophrenia? Curr Drug Targets CNS Neurol Disord 1: 215-225.

Shoval G, Weizman A (2005). The possible role of neurotrophins in the pathogenesis and therapy of schizophrenia. Eur Neuropsychopharmacol 15: 319-329.

Spauwen J, Krabbendam L, Lieb R, Wittchen HU, Van Os J (2004). Early maternal stress and health behaviours and offspring expression of psychosis in adolescence. Acta Psychiatr Scand 110: 356-364.

Swanson CJ, Bures M, Johnson MP, Linden AM, Monn JA, Schoepp DD (2005). Metabotropic glutamate receptors as novel targets for anxiety and stress disorders. Nat Rev Drug Discov 4: $131-144$.

Szyf M (2011). DNA methylation, the early-life social environment and behavioral disorders. J Neurodev Disord 3: 238-249.

Toki S, Morinobu S, Imanaka A, Yamamoto S, Yamawaki S, Honma K (2007). Importance of early lighting conditions in maternal care by dam as well as anxiety and memory later in life of offspring. Eur J Neurosci 25: 815-829.

Tremolizzo L, Doueiri MS, Dong E, Grayson DR, Davis J, Pinna G et al (2005). Valproate corrects the schizophrenia-like epigenetic behavioral modifications induced by methionine in mice. Biol Psychiatry 57: 500-509.

Vallée M, Maccari S, Dellu F, Simon H, Le Moal M, Mayo W (1999). Long-term effects of prenatal stress and postnatal handling on age-related glucocorticoid secretion and cognitive performance: a longitudinal study in the rat. Eur J Neurosci 11: 2906-2916.

Van den Buuse M (2010). Modeling the positive symptoms of schizophrenia in genetically modified mice: pharmacology and methodology aspects. Schizophr Bull 36: 246-270.

Van Os J, Kenis G, Rutten BP (2010). The environment and schizophrenia. Nature 468: 203-212.

Veldic M, Kadriu B, Maloku E, Agis-Balboa RC, Guidotti A, Davis JM et al (2007). Epigenetic mechanisms expressed in basal ganglia GABAergic neurons differentiate schizophrenia from bipolar disorder. Schizophr Res 91: 51-61.

Weaver IC, Meaney MJ, Szyf M (2006). Maternal care effects on the hippocampal transcriptome and anxiety-mediated behaviors in the offspring that are reversible in adulthood. Proc Natl Acad Sci USA 103: $3480-3485$.

Zuena AR, Mairesse J, Casolini P, Cinque C, Alemà GS, MorleyFletcher S et al (2008). Prenatal restraint stress generates two distinct behavioral and neurochemical profiles in male and female rats. PLoS One 3: e2170. 